\title{
The Relationship Between Older Adults' Knowledge of Their Drug Coverage and Medication Cost Problems
}

\author{
John D. Piette, PhD, and Michele Heisler, MD, MPA \\ (See editorial comments by Dr. Richard Stefanacci on pp 166-168)
}

OBJECTIVES: To determine whether chronically ill patients have gaps in knowledge about their prescription drug coverage and establish the relationship between gaps and medication cost problems.

DESIGN: Nationwide, cross-sectional survey.

SETTING: Nationwide survey conducted via the Internet. PARTICIPANTS: Three thousand one hundred nineteen adults aged 50 and older $(1,400$ of whom were aged $\geq 65)$ who had prescription drug coverage and at least one chronic illness.

MEASUREMENTS: Patients were asked about features of their drug benefits and whether they had experienced problems due to medication costs in the prior year.

RESULTS: Twenty-five percent of respondents reported not knowing their usual prescription copayments, and $41 \%$ did not know whether there were caps on their drug coverage. Nonwhite race and lower income were independent risk factors for lack of knowledge about these aspects of pharmacy benefits. Lack of knowledge regarding the limits of coverage was associated with a greater likelihood of cutting back on medication use because of cost pressures, forgoing basic needs because of medication costs, borrowing money to pay for prescriptions, and worrying about medication costs $($ all $P<.05)$.

CONCLUSION: Many older adults with prescription drug coverage do not know important features of their pharmacy benefits. Racial minorities and those with low incomes may have the greatest difficulty understanding coverage and as a result may be at greatest risk for underusing their benefits. Education about Medicare reforms and other efforts to increase prescription coverage should accompany these policies. J Am Geriatr Soc 54:91-96, 2006.

Key words: medication adherence; Medicare; insurance; cost of care

From the Department of Veterans Affairs Center for Practice Management and Outcomes Research, Ann Arbor, Michigan; and Department of Internal Medicine, and Michigan Diabetes Research and Training Center, University of Michigan, Ann Arbor, Michigan.

Address correspondence to Dr. Piette, Center for Practice Management and Outcomes Research, VA Ann Arbor Healthcare System, PO Box 130170,

Ann Arbor, MI 48113. E-mail: jpiette@umich.edu

DOI: $10.1111 / j .1532-5415.2005 .00527 . x$
$\mathrm{O}$ ut-of-pocket medication costs and the structure of patients' prescription drug benefits significantly influence medication adherence ${ }^{1-3}$ and health outcomes. ${ }^{4-6}$ As a consequence, adequate prescription medication coverage is critical for older adults with chronic medical problems. The planned Medicare prescription drug benefit thus represents an important effort to address older adults' problems due to medication cost pressures. ${ }^{7}$

To be effective, a prescription drug policy must define a package of benefits that enhances patients' access to needed drugs, minimizes inappropriate drug use, and is financially viable for the payer. To address these potentially conflicting requirements, most prescription drug plans are complex and include various limits on coverage, such as copayments, payment caps, and incentives to use lower-cost alternatives (e.g., generics). Studies of primarily younger ${ }^{8-10}$ and older adults ${ }^{11,12}$ suggest that many individuals have only a minimal understanding of their health insurance benefits. Prescription drug benefits may be especially difficult to comprehend, and the planned Medicare prescription drug benefit has been widely criticized because of its complexity. ${ }^{13-15}$

Little is known about whether older adults with prescription coverage understand the policies they currently have or how gaps in patients' knowledge of their pharmacy benefits influence their responses to cost pressures. Accordingly, in a nationwide sample of older adults with prescription drug coverage, the current study examined the prevalence of and risk factors for gaps in patients' understanding of their prescription drug costs and benefits and the association between gaps in understanding pharmacy benefits and medication cost problems, including nonadherence, cutting back on basic needs, and borrowing money to pay for prescription drugs.

\section{METHODS}

\section{Participants}

Institutional review boards at Stanford University and the Department of Veterans Affairs (VA) Ann Arbor Healthcare System approved the study protocol. The study was based on surveys completed over the Internet by a nationwide panel of older adults living in the United States. Details 
about the panel's recruitment and representativeness have been reported previously, along with prevalence estimates of problems due to medication costs such as cost-related nonadherence and forgoing basic needs due to cost pressures. ${ }^{1,16}$ All 5,644 panel members aged 50 and older who reported taking prescription medication for diabetes mellitus, depression, heart problems, hypertension, or high cholesterol were identified. A total of 4,264 people $(76 \%)$ completed the on-line informed consent and questionnaire. Respondents were more likely than nonrespondents to be white $(88 \%$ vs $81 \%, P<.001)$, older (mean age 65 vs 63 , $P<.001)$, and to have some college education $(66 \%$ vs $60 \%, P<.001)$. Respondents and nonrespondents were similar with regard to sex $(P=.29)$, home ownership $(P=.44)$, marital status $(P=.16)$, and income $(P=.41)$. A total of 3,291 respondents were identified for the current study, because they answered positively to the question, "Do you have any health insurance that helps pay for prescription medications?" Of these, 151 respondents were excluded, because they reported that they did not have any medical insurance (and therefore may have reported prescription drug coverage in error) and 21 because of missing data on income. The final sample included 3,119 older adults.

\section{Survey Items}

\section{Gaps in Knowledge About Drug Copayments and Coverage}

Surveys included no instructions encouraging or prohibiting respondents from identifying information about their drug coverage from their insurance card or other available descriptions of their policies. Patients were considered to have a gap in their understanding of their usual cost per prescription if they responded "I don't know" to either of the following questions: "About how much do you usually pay out of pocket (money that isn't reimbursed later) when you get a brand name prescription medication?" or "About how much do you usually pay out of pocket (money that isn't reimbursed later) when you get a generic medication?" Participants were coded as having a gap in knowledge about their drug coverage's spending limits if they responded "I don't know" to either of the following questions: "Some health insurance plans stop paying for medication after you reach a certain amount. Does your insurance have a limit on the total cost of medication that it will pay for?" or "Some health insurance plans have a limit on the number of different medications they will pay for each month. Does your health insurance plan limit the number of medications it will pay for?" Limits on the number of medications covered have been noted as a problem with some Medicaid prescription drug plans. ${ }^{17-19}$

\section{Medication Cost Problems and Covariates}

Respondents were coded as having cost-related adherence problems if they reported medication underuse due to cost in the prior year for prescription drugs treating any of 16 common chronic illnesses. Respondents also were asked about other potential problems due to medication costs, including spending less on basic needs such as food or heat to pay medication costs, borrowing money from family or friends to pay medication costs, and worrying about how to pay for medications at least once per month. The wording of these items is provided in footnotes to Table 3. Potential covariates included measures of patients' sociodemographic characteristics (race, sex, educational attainment, age), clinical characteristics (number of diagnoses, number of prescription drugs), and relevant financial characteristics (income, type of health insurance coverage, total monthly out-of-pocket medication costs). Household income was assessed via a survey item asking patients to report their total household income within specified categories. For health insurance, patients were categorized into the following hierarchical groups: VA health care, Medicaid (without VA care), Medicare (without VA or Medicaid), and private insurance (only).

\section{Statistical Analyses}

Initial bivariate analyses examined differences across patient subgroups in the proportion of patients reporting gaps in knowledge about their medication copayments and coverage limits. Multivariate logistic regression models were then constructed to identify the independent association between each patient characteristic and each of these two knowledge gaps.

In the second phase of the analysis, logistic models were fit to assess the extent to which patients' lack of knowledge about these two aspects of their drug coverage was independently associated with their likelihood of reporting problems due to medication cost. Each logistic model controlled for potential confounding by patients' sociodemographic characteristics, number of medications, total monthly medication costs, and insurance type. Because these issues are particularly salient for potential beneficiaries of the Medicare prescription drug benefit, analyses addressed each research question in the overall sample and separately for the 1,400 respondents who were aged 65 and older. To correct for the multiple comparisons across the two samples, $P<.025$ (i.e., $.05 \div 2$ ) was considered statistically significant. No corrections were made for the multiple other associations tested within or across Tables 1 and 2. Auxiliary analyses examined variation in the association between knowledge gaps and medication cost problems across strata defined by covariates and tested for interactions between knowledge gaps and respondents' income. No evidence of interactions between the potential risk factors for medication cost problems was identified.

\section{RESULTS}

\section{Patient Description}

In the overall sample, $88 \%$ of respondents were white, $51 \%$ were men, and $32 \%$ had at most a high school education. A total of $45 \%$ were aged 65 and older, and a wide income range was represented, with $40 \%$ of the sample reporting annual household incomes of less than $\$ 40,000$. Nearly two thirds $(64 \%)$ of the sample reported having private medical insurance, with $8 \%$ on Medicaid alone, $7 \%$ on Medicare alone, and $6 \%$ receiving care only at the VA. Seventy-four percent were taking at least three prescription medications, and $47 \%$ reported monthly out-of-pocket medication costs of greater than $\$ 50$. Patients who were aged 65 and older were similar demographically to the overall sample, although only $24 \%$ had annual household incomes of 
Table 1. Proportion of Respondents with Gaps in Knowledge About the Characteristics of Their Prescription Drug Benefits

\begin{tabular}{|c|c|c|c|c|c|c|c|c|}
\hline \multirow[b]{2}{*}{ Respondent Characteristic } & \multicolumn{4}{|c|}{$\begin{array}{c}\text { Gap in Knowledge About Usual } \\
\text { Copayments }\end{array}$} & \multicolumn{4}{|c|}{ Gap in Knowledge About Spending Limits } \\
\hline & All \% & $P$-value & $\geq 65 \%$ & $P$-value & All \% & $P$-value & $\geq 65 \%$ & $P$-value \\
\hline Total & 25 & & 29 & & 41 & & 38 & \\
\hline Race & & .01 & & .41 & & .002 & & .003 \\
\hline White & 24 & & 28 & & 40 & & 37 & \\
\hline Nonwhite & 30 & & 32 & & 49 & & 51 & \\
\hline Sex & & .10 & & .01 & & .14 & & .29 \\
\hline Male & 23 & & 26 & & 40 & & 37 & \\
\hline Female & 26 & & 33 & & 42 & & 39 & \\
\hline Education & & .001 & & .20 & & .006 & & .13 \\
\hline$\leq$ High school & 28 & & 31 & & 44 & & 40 & \\
\hline Some college & 25 & & 29 & & 42 & & 39 & \\
\hline$\geq$ College & 20 & & 26 & & 37 & & 34 & \\
\hline Age & & $<.001$ & & & & .003 & & \\
\hline $50-54$ & 20 & & - & & 45 & & - & \\
\hline $55-64$ & 23 & & - & & 43 & & - & \\
\hline$\geq 65$ & 26 & & - & & 38 & & - & \\
\hline Income, \$ & & $<.001$ & & .17 & & $<.001$ & & .002 \\
\hline$\geq 60,000$ & 20 & & 25 & & 37 & & 33 & \\
\hline $40,000-59,999$ & 23 & & 28 & & 39 & & 34 & \\
\hline $20,000-39,999$ & 26 & & 29 & & 43 & & 39 & \\
\hline$<20,000$ & 34 & & 34 & & 51 & & 48 & \\
\hline Medications, $\mathrm{n}$ & & .06 & & .001 & & .14 & & .41 \\
\hline $1-2$ & 22 & & 22 & & 41 & & 35 & \\
\hline $3-6$ & 25 & & 29 & & 42 & & 39 & \\
\hline$\geq 7$ & 27 & & 35 & & 38 & & 39 & \\
\hline Insurance & & $<.001$ & & .55 & & .33 & & .20 \\
\hline Department of Veterans Affairs & 30 & & 30 & & 46 & & 40 & \\
\hline Medicaid & 37 & & 33 & & 43 & & 40 & \\
\hline Private & 22 & & 28 & & 40 & & 39 & \\
\hline Medicare & 31 & & 30 & & 43 & & 43 & \\
\hline Monthly out-of-pocket cost, \$ & & $<.001$ & & $<.001$ & & .40 & & .53 \\
\hline $1-50$ & 22 & & 23 & & 40 & & 37 & \\
\hline $51-99$ & 25 & & 30 & & 43 & & 39 & \\
\hline$\geq 100$ & 30 & & 42 & & 42 & & 40 & \\
\hline
\end{tabular}

Note: To correct for the multiple comparisons across the two samples, $P<.025$ (i.e., $.05 \div 2$ ) were considered statistically significant.

$\$ 60,000$ or more, compared with $34 \%$ of respondents in the overall sample.

\section{Knowledge Gaps About Medication Costs and Coverage Limits}

Twenty-five percent of respondents in the overall sample and $29 \%$ of those aged 65 and older reported not knowing their usual out-of-pocket prescription drug copayments (Table 1). In bivariate analyses, respondents were more likely to lack knowledge about their usual cost per prescription if they were nonwhite, had less education, were older, or had lower incomes (all $P<.025$ ). Patients with VA coverage, Medicaid, or Medicare were more likely to report that they did not know their usual prescription copayments than those with private health insurance. Respondents with higher total monthly out-of-pocket medication costs were more likely to report not knowing their usual copayment per prescription than those with lower total medication costs. For patients aged 65 and older, female sex, more medications, and higher total monthly out-of-pocket medication costs were associated with gaps in knowledge about medication copayments (all $P \leq .001$ ).

Forty-one percent of all respondents and $38 \%$ of those aged 65 and older had a gap in knowledge about whether there were limits on the number of medications or total medication costs that their prescription plans would cover. Nonwhites, those with less education, those who were younger, and those with lower incomes were more likely to report not knowing about benefit caps (all $P \leq .003$ ). Of respondents aged 65 and older, nonwhites and those with lower incomes were more likely to report that they did know whether their insurance plan had benefit caps (both $P \leq .003)$.

In the overall sample, nonwhite race was independently associated with a significant increase in respondents' odds of having a gap in knowledge about their usual copayments (Table 2). Lower educational attainment, low income, 
Table 2. Adjusted Odds Ratios for the Association Between Patient Characteristics and Gaps in Knowledge About Prescription Drug Coverage

\begin{tabular}{|c|c|c|c|c|}
\hline \multirow[b]{2}{*}{ Patient Characteristic } & \multicolumn{2}{|c|}{$\begin{array}{c}\text { Gap in Knowledge About } \\
\text { Usual Copayment }\end{array}$} & \multicolumn{2}{|c|}{$\begin{array}{l}\text { Gap in Knowledge About } \\
\text { Spending Limits }\end{array}$} \\
\hline & All & $\geq 65$ & All & $\geq 65$ \\
\hline Nonwhite & $1.4^{*}$ & 1.1 & $1.3^{*}$ & $1.8^{\dagger}$ \\
\hline Female & 1.1 & 1.3 & 1.1 & 1.0 \\
\hline \multicolumn{5}{|l|}{ Education (ref $\geq$ college) } \\
\hline Some college & 1.2 & 1.0 & 1.2 & 1.2 \\
\hline$\leq$ High school & $1.4^{\dagger}$ & 1.2 & 1.2 & 1.2 \\
\hline \multicolumn{5}{|l|}{ Age (ref 50-54) } \\
\hline $55-64$ & 1.0 & - & 0.9 & - \\
\hline$\geq 65$ & $1.4^{\dagger}$ & - & $0.7^{\ddagger}$ & - \\
\hline \multicolumn{5}{|l|}{ Income, $\$$ (ref $\geq 60,000)$} \\
\hline $40,000-59,999$ & 1.1 & 1.1 & 1.1 & 1.0 \\
\hline $20,000-39,999$ & 1.1 & 1.0 & $1.3^{\dagger}$ & 1.2 \\
\hline$<20,000$ & $1.4^{\dagger}$ & 1.2 & $1.8^{\ddagger}$ & $1.7^{\dagger}$ \\
\hline \multicolumn{5}{|l|}{ Medications (ref 1-2) } \\
\hline $3-6$ & 1.1 & 1.3 & 1.0 & 1.1 \\
\hline$\geq 7$ & 1.0 & $1.5^{*}$ & $0.7^{\dagger}$ & 1.1 \\
\hline \multicolumn{5}{|l|}{ Insurance (ref private) } \\
\hline VA & 1.4 & 1.2 & 1.1 & 1.1 \\
\hline Medicaid & $1.7^{\ddagger}$ & 1.3 & 1.3 & 1.0 \\
\hline Medicare & 1.2 & 1.1 & 1.0 & 1.2 \\
\hline \multicolumn{5}{|c|}{ Monthly out-of-pocket cost, \$ (ref 1-50) } \\
\hline $51-99$ & 1.2 & 1.3 & 1.2 & 1.1 \\
\hline$\geq 100$ & $1.6^{\ddagger}$ & $2.2^{*}$ & 1.1 & 1.1 \\
\hline
\end{tabular}

$P<{ }^{*} .025,{ }^{\dagger} .01,{ }^{\ddagger} .001$; to correct for the multiple comparisons across the two samples, $P<.025$ (i.e., $.05 \div 2$ ) was considered statistically significant. ref $=$ reference.

Medicaid coverage, and high out-of-pocket costs were each independent risk factors for gaps in knowledge about copayments. In the subgroup of respondents aged 65 and older, a larger number of prescriptions and high out-ofpocket costs were the only risk factors independently associated with this knowledge gap.

In the overall sample, nonwhite race and lower income were also independent risk factors for a gap in knowledge about spending caps on coverage; respondents who were older and using more medications were less likely to report gaps in knowledge about spending caps. In the subgroup aged 65 and older, nonwhites had nearly twice the adjusted odds of having a gap in knowledge about spending limits as their white counterparts $(P=.005)$. Similarly, those with incomes less than $\$ 20,000$ had significantly greater odds of having this knowledge gap than those with incomes of $\$ 60,000$ or more $(P=.01)$.

\section{The Association Between Gaps in Knowledge and Medication Cost Problems}

In the overall sample, $14 \%$ of respondents reported cutting back on prescription medication use because of cost, $15 \%$ reported forgoing basic needs because of medication cost pressures, $5 \%$ reported borrowing money from family or friends to pay medication costs, $8 \%$ reported increasing their credit card debt to pay these costs, and $16 \%$ reported worrying about medication costs at least once per month. Ten percent of respondents aged 65 and older reported cutting back on prescription medication use because of cost, $11 \%$ reported forgoing basic needs because of medication cost pressures, $2 \%$ reported borrowing money from family or friends to pay medication costs, $6 \%$ reported increasing their credit card debt to pay these costs, and $13 \%$ reported worrying about medication costs at least once per month.

In the overall sample and among respondents aged 65 and older, lack of knowledge about usual out-of-pocket costs for prescription medication was not associated with cost-related underuse or other medication cost problems (Table 3), but respondents who reported not knowing their drug plan's spending limits were at significantly greater risk for each of the five medication cost problems.

\section{DISCUSSION}

In an effort to optimize medication coverage while minimizing overall insurance costs, many prescription drug policies include features designed to increase cost sensitivity of patients and their physicians. Unfortunately, these limits on coverage often complicate policies in ways that may be difficult for beneficiaries to understand. In the current study, a large proportion of older adults with prescription drug benefits had gaps in their knowledge about their medication copayments and the limits on their insurance coverage.

Socioeconomically vulnerable respondents were the most likely to have gaps in knowledge about their prescription drug coverage. In the group aged 65 and older, racial minority respondents and those with low incomes were 
Table 3. Independent Association Between Gaps in Knowledge and Medication Cost Problems

\begin{tabular}{|c|c|c|c|}
\hline Underus & $\begin{array}{l}\text { Basic } \\
\end{array}$ & Borrow & $\begin{array}{c}\text { Credit Card } \\
\text { Debt }^{\ddagger}\end{array}$ \\
\hline
\end{tabular}

Gap in Knowledge

Adjusted Odds Ratio (95\% Confidence Interval)

\begin{tabular}{llllll}
\hline About usual copayments & & & & \\
$\quad$ All respondents & $1.0(0.8-1.3)$ & $1.1(0.9-1.4)$ & $1.0(0.7-1.6)$ & $0.8(0.6-1.1)$ & $1.1(0.9-1.4)$ \\
$\quad$ Aged $\geq 65$ & $1.3(0.9-1.9)$ & $1.3(0.9-1.9)$ & $0.5(0.2-1.2)$ & $0.8(0.5-1.4)$ & $1.4(1.0-1.9)$ \\
About spending limits & & & & & \\
$\quad$ All respondents & $1.7(1.4-2.1)^{\#}$ & $1.9(1.5-2.4)^{\#}$ & $2.0(1.4-2.9)^{\#}$ & $1.4(1.1-1.9)^{\|}$ & $1.7(1.3-2.0)^{\#}$ \\
$\quad$ Aged $\geq 65$ & $1.6(1.1-2.3)^{\bullet}$ & $2.2(1.5-3.2)^{\#}$ & $2.5(1.1-5.9)^{\|}$ & $1.4(0.9-2.4)$ & $1.7(1.2-2.4)^{\bullet}$
\end{tabular}

Note: Each logistic regression model controlled for patients' sociodemographic characteristics (race, sex, educational attainment, and income), number of prescription medications, total monthly out-of-pocket drug costs, and insurance type.

* "In the past 12 months, did you ever spend less on food, heat, or other basic needs so that you would have enough money to pay for your prescription medications?"

$\dagger$ "In the past 12 months, did you ever borrow money from a family member or friend to pay for your prescription medications?"

‡ "In the past 12 months, did you ever increase the amount of credit card debt you carried from month to month because of the cost of your prescription medications?"

$\S$ "In the past 12 months, how often did you worry about paying for your prescription medications?"

$P<\|$.025, ${ }^{\circledR} .01,{ }^{\#} .001$. To correct for the multiple comparisons across the two samples, $P<.025$ (i.e., .05 $\div 2$ ) was considered statistically significant.

substantially more likely than other respondents to have a gap in knowledge about their medication benefit's spending limits. Spending caps associated with the planned Medicare drug policy have been highlighted as particularly confusing; copayments for beneficiaries with incomes above $150 \%$ of the federal poverty level will increase to $100 \%$ after their annual drug costs exceed $\$ 2,250$, until they reach $\$ 5,100$ (the "doughnut hole"), and then decrease to $5 \% .{ }^{13}$ Based on findings from the current study, it is possible that a significant number of beneficiaries may not understand those limits - even if they are able to track their own accumulating drug expenditures over time.

The large proportion of older adults reporting gaps in knowledge about their drug coverage spending limits is particularly troubling, because respondents with these gaps were more likely to also report problems due to medication costs. Patients who were unaware of limits on their drug coverage were more likely to forgo medication because of cost pressures, to forgo basic needs because of medication costs, to borrow money to pay for their prescriptions, and to worry about paying for their drugs. This pattern of effects is consistent with those found in a previous study. ${ }^{12} \mathrm{In}$ that study, patients' perception of their emergency department copayment was a stronger predictor of emergency department use than their actual copayment level, and those who anticipated a larger copayment were at risk for avoiding or delaying emergency care. The current study's findings raise similar concerns that some older adults may underuse their drug benefits, because they do not understand - and underestimate - the ways in which their drug plan could reduce the financial strain of their drug costs.

Clinicians, health systems, and public health organizations may be able to partially address patients' medication cost problems by educating patients about the benefits they have. Unfortunately, recent studies suggest that patients do not discuss medication cost problems with their physicians, ${ }^{20}$ that clinicians fail to identify patients facing problems, ${ }^{21,22}$ and that clinicians report significant barriers to assisting patients struggling with out-of-pocket costs. ${ }^{23}$ Many physicians are unaware of the cost of common prescriptions and are therefore unlikely to take costs into account when prescribing. ${ }^{24}$ Moreover, many physicians' primary strategy to minimize patients' medication costs is to give free samples. Because usually only expensive, newer medications are available as free samples, this strategy (although often appreciated by patients) can lead to increased costs for patients over the longer term. ${ }^{20,25}$ Multifaceted interventions addressing provider barriers to cost-effective prescribing and patient barriers to appropriate use of available pharmacy benefits may be required to fully address patients' medication cost problems. As part of this effort, it will be critical to develop effective campaigns to educate older adults about the planned Medicare drug policy. These initiatives may be particularly important for older adults at highest risk for gaps in knowledge and for significant burdens from their out-of-pocket medication costs: people of color, those with low incomes, and those on multiple medications.

It is not clear why the two measures of patients' understanding of their drug coverage differed with respect to the relationship with medication cost problems. It may be that patients' concerns about exceeding their (unknown) coverage limits lead them to underuse their benefits. In contrast, lack of information about usual copayments may reflect patients' overall understanding of their resources but without the accompanied concern about impending catastrophic costs that exceeding a limit could signify. Future research will be important to understand the ways in which these two dimensions of patients' knowledge of their coverage (as well as understanding of other dimensions of their insurance) affect their decision-making about medication adherence and other responses to medication costs.

This study has several limitations. First, the analyses may underestimate the proportion of older adults with problems understanding their drug coverage, because respondents who reported that they did not have pharmacy benefits were excluded. Some of those respondents may have had drug benefits of which they were unaware. Respondents were classified as having a gap in their knowledge about copayments and spending caps only if they explicitly reported that they did not know; other respondents who provided estimates may have reported erroneous information. Also, the survey was conducted over the Internet, and older adults who did not respond because of discomfort 
using computers may also have been more likely to have problems understanding their prescription drug coverage. Unmeasured patient characteristics, such as health literacy or non-cost-related adherence problems, may account for some of the relationship between patients' understanding of their drug coverage and their likelihood of experiencing problems due to medication costs. Although prior studies have linked cost-related medication underuse with adverse health outcomes, ${ }^{4,5}$ the current study included no information about adverse outcomes associated with patients' gaps in knowledge about their prescription coverage.

Patients may be more likely to know the limits of their drug coverage when they are nearing those thresholds or have already exceeded the limits on their benefits. Unfortunately, the current study included no information about the details of patients' history of medication costs or their insurance policies. If knowledge about drug coverage is a proxy for less-generous benefits, rather than an independent determinant of patients' behavior, it would be expected that reported knowledge (rather than knowledge gaps) would be a risk factor for the medication cost problems described in Table 3. Future studies using samples of patients with clearly similar drug coverage would shed light on whether reporting biases in the current study affected estimates of the associations between drug coverage knowledge gaps and medication cost problems.

In conclusion, the current study found that many chronically ill older patients with prescription drug coverage have gaps in knowledge about their current medication costs and benefits. Socioeconomically vulnerable patients are especially at risk. Patients who report problems understanding their prescription coverage are more likely to cut back on medication use and to experience other problems because of cost pressures. In light of the complexity of the planned Medicare prescription drug program, government agencies and other organizations should make intensive efforts to educate Medicare recipients and enable them to take full advantage of the new benefits.

\section{ACKNOWLEDGMENTS}

This study was funded by the VA Health Services Research and Development (HSR\&D) Service. John Piette is a VA HSR \&D Career Scientist and Michele Heisler is a VA HSR \&D Career Development Awardee. The views expressed in this article are those of the authors and do not necessarily represent the views of the VA.

Financial Disclosure: Drs. Piette and Heisler have no financial support for research, consultantships, speakers forums, or other holdings that might be a conflict of interest with respect to this study.

Authors Contributions: Dr. Piette was responsible for acquiring research funding, administering the study, designing the survey, conducting data analyses, and preparing the manuscript. Dr. Heisler participated in developing the survey, interpreting analytic results, and making substantive additions and revisions to the paper.
Sponsor's Role: All issues of study design, analysis, and writing of the manuscript were solely the responsibility of Dr. Piette and Dr. Heisler.

\section{REFERENCES}

1. Piette JD, Heisler M, Wagner TH. Cost-related medication under-use among chronically-ill adults. What treatments do people forgo? How often? Who is at risk? Am J Public Health 2004;94:1782-1787.

2. Huskamp HA, Deverka PA, Epstein AM et al. The effect of incentive-based formularies on prescription-drug utilization and spending. N Engl J Med 2003;349:2224-2232.

3. Goldman DP, Joyce GF, Escarce JJ et al. Pharmacy benefits and the use of drugs by the chronically ill. JAMA 2004;291:2344-2350.

4. Tamblyn R, Laprise R, Hanley JA et al. Adverse events associated with prescription drug cost-sharing among poor and elderly persons. JAMA 2001;285:421-429.

5. Heisler M, Langa K, Eby EL. The health effects of restricting prescription medication use because of cost. Med Care 2004;42:626-634.

6. Piette JD, Wagner TH, Potter MB et al. Health insurance status, medication self-restriction due to cost, and outcomes among diabetes patients in three systems of care. Med Care 2004;42:102-109.

7. Iglehart JK. Prescription drug coverage for Medicare beneficiaries. N Engl J Med 2003;349:923-925.

8. Meredith LS, Humphrey N, Orlando $M$ et al. Knowledge of health care benefits among patients with depression. Med Care 2002;40:338-346.

9. Garnick DW, Hendricks AM, Thorpe KE et al. How well do Americans understand their health coverage? Health Aff (Millwood) 1993;12:204-212.

10. Marquis MS. Consumers' knowledge about their health insurance coverage. Health Care Financ Rev 1983;5:65-80.

11. McCormack LA, Uhrig JD. How does beneficiary knowledge of the Medicare program vary by type of insurance? Med Care 2003;41:972-978.

12. Hsu J, Reed M, Brand R et al. Cost sharing. patient knowledge and effects on seeking emergency department care. Med Care 2004;42:290-296.

13. Moon M. How beneficiaries fare under the new Medicare drug bill. Issue Brief (Commonw Fund) 2004; June:1-15.

14. Freudenheim M. Drug discount for elderly may confuse as well as help. New York Times, February 6, 2004.

15. Leland J. 73 options for medicare plan fuel chaos, not prescriptions. New York Times, May 12, 2004.

16. Heisler M, Wagner T, Piette JD. Patient strategies to cope with high prescription medication costs. Who is cutting back on necessities, increasing debt, or underusing medications? J Behav Med 2005;28:43-51.

17. Soumerai SB, McLaughlin TJ, Ross-Degnan D et al. Effects of limiting Medicaid drug-reimbursement benefits on the use of psychotropic agents and acute mental health services by patients with schizophrenia. N Engl J Med 1994;331:650-655.

18. Soumerai SB, Ross-Degnan D, Avorn J et al. Effects of Medicaid drug-payment limits on admission to hospitals and nursing homes. $\mathrm{N}$ Engl J Med 1991;325:1072-1077.

19. Soumerai SB, Avorn J, Ross-Degnan D et al. Payment restrictions for prescription drugs under Medicaid. Effects on therapy, cost, and equity. N Engl J Med 1987;317:550-556.

20. Piette JD, Heisler M, Wagner TH. Cost-related medication under-use. Do patients with chronic illnesses tell their doctors? Arch Intern Med 2004;164:1749-1755.

21. Heisler ME, Wagner TH, Piette JD. Clinician identification of patients with chronic illnesses who face problems paying for prescription medications. Am J Med 2004;116:753-758.

22. Alexander GC, Casalino LP, Meltzer DO. Patient-physician communication about out-of-pocket costs. JAMA 2003;290:953-958.

23. Alexander GC, Casalino LP, Tseng CW et al. Barriers to patient-physician communication about out-of-pocket costs. J Gen Intern Med 2004;19: $856-860$.

24. Reichert S, Simon T, Halm EA. Physicians' attitudes about prescribing and knowledge of the costs of common medications. Arch Intern Med 2000;160:2799-2803.

25. Dana J, Loewenstein G. A social science perspective on gifts to physicians from industry. JAMA 2003;290:252-255. 